\title{
Education, Arts and Sustainability: Emerging Practice for a Changing World, by Mary Ann Hunter, Arnold Aprill, Allen Hill \& Sherridan Emery
}

Book Response: Education, Arts and Sustainability: Emerging Practice for a Changing World, by Mary Ann Hunter, Arnold Aprill, Allen Hill \& Sherridan Emery. Springer Singapore, Springer, 2018, 120 pp., ISBN: 9811077096

Dr. Kudrat-E-Khuda Babu, Daffodil International University kekbabu@gmail.com

Keywords: Australia; Arts; Critical Thinking; Education; Partnership; Sustainability.

Figure 1

Book cover

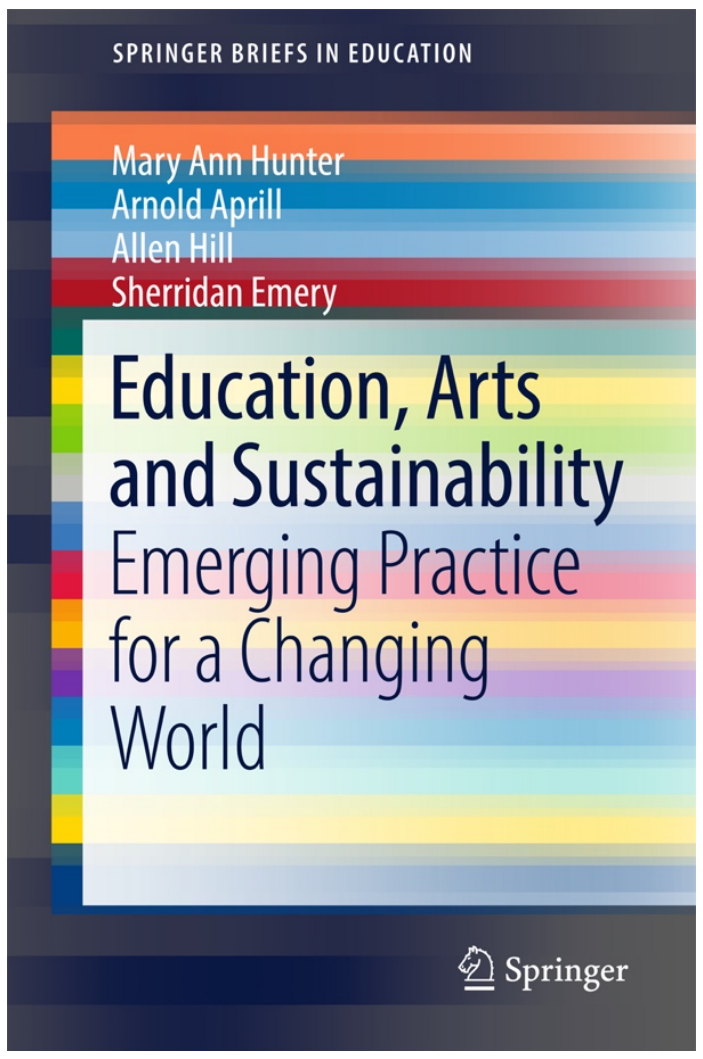

$E$

ducation, Arts and Sustainability: Emerging Practice for a Changing World (2018) endeavors to address how to integrate arts and education for sustainability through illustrated case-studies. In light of new practices in the contemporary world, and various forms of arts and cultures, the existing book examines problems in education (i.e., 
education design, financial crises, health care, hunger, income disparity, obesity, poverty, sustainability, etc.). In particular, the authors highlight how generative arts experiences in schoolwhether they be curricular, co-curricular, or community-led - offer students conceptual and experiential engagement. Moreover, the authors focus on how sustainability principles are embedded in contemporary arts, education, comprehension, and pedagogy. Considering the certainty of the arts and education in life, this book is not only a precious edition in Australia and New Zealand but also in other countries including the UK, the USA, Canada, Bangladesh, and India. However, the book's discussions of practical education and the role of the arts in society, as well as its repercussions, are intended to be vital resources for academics, researchers, students, artists, and policymakers. It is true that education is the key to raising consciousness and empowering individuals and societies to act in the global context of acute social, economic, and environmental crises. Yet, how would this take place when both the uncertainty and desire for positive reform become immense, and the encouragement of the status quo is complicit in schooling systems? The issues and queries stated above have been a focused in this book in a systematic manner. Moreover, the authors have included some case studies; relevant figures; tables, and references in their book for better understanding. Regarding case examples, chapters five to seven turn to practice by each presenting a case example of an arts-based inquiry in which one of the Australian Research Institute for Education for Sustainability (ARIES) principles are embedded. These principles include participation, systems thinking, critical thinking, envisioning better futures, and partnerships for change (ARIES, 2009). Sometimes, these principles are explicit in the intent of the documented project, such as Story of a Smartphone in Chapter 5. In this project description, primary school students engaged with the principle of systems thinking to make and perform art as a response to their understanding of the life cycle of a mobile phone. Other encounters are community-initiated, such as the Billy Project in Chapter 3, which describes an intergenerational arts project that demonstrates the sustainability principle of participation by bringing children together with their families, elders from nearby aged care homes, artists, and long-term unemployed community members to build go-karts at the school (Hunter et al, 2018).

The authors recount a series of case scenarios based on critical education theory and precepts of creativity, inquiry, and change. All of these examples show how art practices in schools are based on five principles of sustainability education: critical thinking, systems thinking, community partnership, participation, and visualizing better futures. It is hard for educators, policymakers, and researchers to understand the norms and principles of education, arts, and sustainability from the usual books (e.g., the usual education books and the usual textbooks that are studied in education training programs). Nonetheless, this existing book, alternatively, provides an in-depth analysis of art education and is noteworthy in its ability to help the educators, learners, policymakers, and researchers to understand the key norms and the key principles of education, arts, and sustainability emerging practice in the current era in both nationally and internationally. Featuring the creative work and voices of teachers working in arts-based inquiry and diverse community-engaged contexts, the present book investigates how sustainability principles are embedded in contemporary art education thinking and pedagogy. The book is divided into eight chapters. The book's first chapter focuses on the prospects for arts sustainability education and the discussions that follow. The second chapter of this book examines the opportunities and challenges of integrating sustainability education; the general meaning and concept of sustainability; in-depth education and arts in education. The third chapter of the existing book addresses the crafting community with Billy Project; the concept of arts sustainability; participation in action and participation through arts. It also describes results of the meenah Neenah Cultural Arts Program 
(Hunter et al., 2018) and the impact it had on arts education. Critical thinking as cultural and affective engagement are the subjects of chapter four. Regarding critical thinking, the authors Mary Ann Hunter and colleagues (Hunter et al, 2018) argue that critical thinking is acclaimed as a highly valued twenty-first-century skill. In a world of rapidly developing digital technologies and multiple ways of accessing information, critical thinking can be key to developing the ability to discern, be logical and evaluate what's appropriate to our purpose or context. Moreover, critical thinking can help people to better understand the world we inhabit and potentially interrogate assumptions and social structures that frame our existence. In chapter five there is a discussion of various facets of systems thinking: the story of a smartphone (Systems Thinking), why there is a need for systems thinking; systems thinking and arts education and systems thinking in action; student-led inquiry and whole school change. By contrast, chapter six illuminates the festival of wood (Envisioning Better Futures) and better futures in action. Chapter seven focuses on issues around teachers' professional development and how it can be overhauled: the importance of partnerships for change, and arts-led teacher professional learning. This chapter also covers the topics 'partnerships for change inaction' and 'valuing artists' as well as 'ways of knowing in making partnerships for change'. In the last chapter of the book, the authors provide a way forward through radical compliance. It also covers re-appropriating innovation; change and anxiety; emergent practice; ethical issues, honesty and integrity; radical compliance; dilemma management; and lastly, necessary failure and risk (Hunter et al, 2018).

Finally, it can be mentioned that the present book addresses the challenges related to art education (i.e., shortage of qualified art teachers, inadequate teaching facilities and funding, poor government, etc.) by proposing the integration of sustainability and arts education in both principle and practice. The book successfully presents an array of issues at the intersections of education, arts and sustainability which are urgent and pertinent to our fast-changing world. It's a world we all share and that is why its relevance goes far beyond the countries the authors have drawn upon for examples.

\section{References}

Australian Research Institute for Environment and Sustainability (ARIES). (2009). Education for Sustainability (EfS).

https://aries.mq.edu.au/about/education_for_sustainability_processes/

Hunter, M. A., Aprill, A., Hill, A., \& Emery, S. (2018). Education, arts and sustainability: Emerging practice for a changing world. Springer.

https://doi.org/10.1007/978-981-10-7710-4_4 